\title{
BIOMARKER AND POLLEN APPROACH TO RECONSTRUCT LATE HOLOCENE CLIMATE AND ENVIRONMENTAL HISTORY IN WESTERN SRI LNKA
}

\author{
Kasun Gayantha ${ }^{1}$, Joyanto Routh ${ }^{2}$, Krishnamurthy Anupama ${ }^{3}$, Jean Lazar ${ }^{3}$, Srinivasan Prasad ${ }^{3}$, \\ Rohana Chandrajith ${ }^{4}$, Patrick Roberts ${ }^{5}$, Gerd Gleixner ${ }^{1}$ \\ 1. Max Planck Institute for Biogeochemistry, Jena, Germany \\ 2. Department of Thematic Studies Environmental Change, Linköping University, Linköping, Sweden \\ 3. French Institute of Pondicherry, Pondicherry, India \\ 4. Department of Geology, University of Peradeniya, Peradeniya, Sri Lanka \\ 5. Max Planck Institute for the Science of Human History, Jena, Germany
}

\section{Introduction}

Climate, environment, and agriculture of Sri Lanka are extremely sensitive for the fluctuation of Indian ocean monsoon intensity. The unique geographical location in the Inter-Tropical Convergence Zone (ITCZ) and the morphology of the island make Sri Lanka an excellent location to track Indian ocean monsoon variability through reconstructing paleoenvironmental and paleoclimate conditions. Combined analysis of organic geochemical proxies together with biological proxies (i.e. pollen) can generate robust evidence about the past climate and its influence on terrestrial ecosystems.

A $4.1 \mathrm{~m}$ long sediment core retrieved from the coastal Lake Bolgoda in southwestern Sri Lanka revealed ca. $3000 \mathrm{yrs}$ BP depositional history. Salinity in this coastal lake is mainly controlled by seawater intrusion due to the fluctuation of the freshwater inflow via stream (Ratnayake et al., 2018). The core was analyzed for various biomarkers ( $n$-alkane, alkanol, alkanoic acids, and sterols) together with compound specific carbon isotopic signatures of $n$-alkane. In addition, a pollen analysis was conducted in selected depth intervals in the core to confirm the biomarker and stable isotope changes. Biomarkers revealed changes of organic matter sources into the Bolgoda Lake, whereas the pollen data provided more specific information about the vegetation that is dominant and less dominant species that were in the catchment and in the lake itself.

\section{Results}

As revealed by the variation of mangrove specific triterpenols (eg; taraxerol, $\boldsymbol{\beta}$-amyrin, germinacol) lacustrine salinity changed rapidly with seawater intrusion to the lake system. High salinity triggered dense mangrove vegetation (Versteegh et al., 2004). Poaceae grass was the major source of organic matter into the watershed throughout the whole period. In addition, mangrove vegetation around the lake, mainly Rhizophoraceae and Avicenniaceae contributed significantly to the input of organic matter. However, the dominance varied coinciding with lacustrine salinity. The catchment was dominant with woody plants/trees belonging to Mallotus, Macaranga, Phoenix, Syzygium, and Areaca but shrubs and small trees of Randia and Ixora dominated during dryer/arid conditions. $\delta^{13} \mathrm{C}$ values of $n-\mathrm{C}_{33}$ and $n-\mathrm{C}_{31}$ alkanes which are dominant in grasses (Sinninghe Damsté et al., 2011) showed a positive correlation with taraxerol. In addition, they showed more positive values during high salinity in the lake induced by low precipitation or dry climatic conditions in the catchment. 


\section{Conclusions}

The overall climatic condition during the last 3000 yrs can be identified as wet but it was interrupted by a dry phase from ca. $2400-2050$ cal yr BP. The lacustrine salinity and catchment vegetation indicated two distinct periods in monsoon output extending from ca. 3000 to $2400 \mathrm{cal}$ yr BP when rainfall increased and strengthened. However, there were short periods of weak rainfall with abrupt changes between from 2400 - 1800 cal yr BP. Between $2400-$ 2050 cal yr BP drier period is strongly evident. This event has good correlation with the Roman Warm Period. The rainfall again intensified and stabilized ca. $1800-1300$ cal yr BP. After that, the monsoons again showed a weakening trend until the present. This study illustrates the effectiveness of using different types of proxies and combining their results to unravel highresolution information about past environmental and climatic changes.

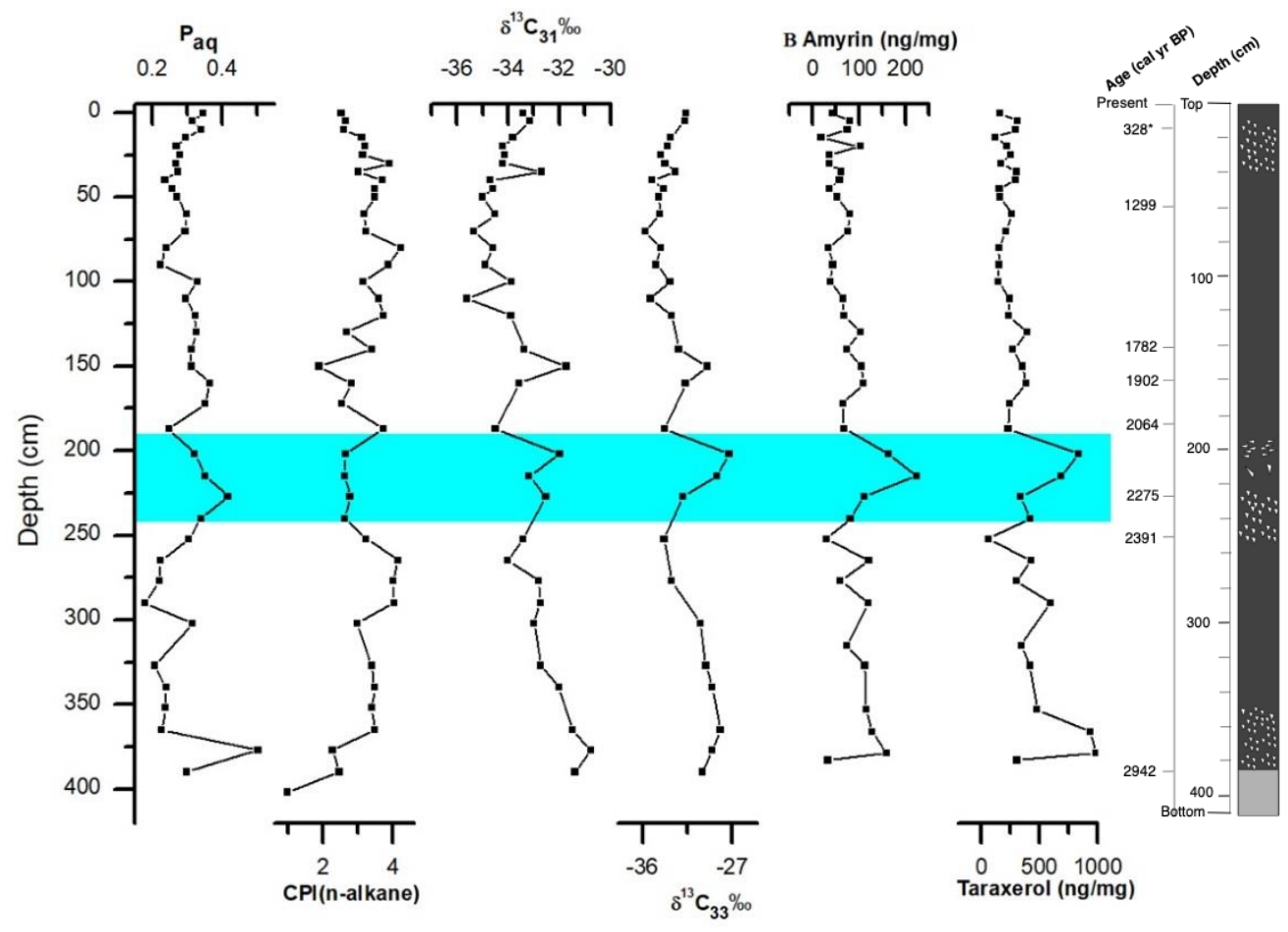

Figure 1. Biomarker trends in Bolgoda Lake used to infer environmental changes: Aquatic plant index $\left(\mathrm{P}_{\mathrm{aq}}\right)$, CPI (n-alkane), $\delta^{13} \mathrm{C}_{31}$ and $\delta^{13} \mathrm{C}_{33}$ of n-alkane, $\boldsymbol{\beta}$-amyrin and taraxerol

\section{References}

Ratnayake, A.S., Ratnayake, N.P., Sampei, Y., Vijitha, A.V.P., Jayamali, S.D., 2018.

Seasonal and tidal influence for water quality changes in coastal Bolgoda Lake system, Sri Lanka. J. Coast. Conserv.

Sinninghe Damsté, J.S., Verschuren, D., Ossebaar, J., Blokker, J., van Houten, R., van der Meer, M.T.J., Plessen, B., Schouten, S., 2011. A 25,000-year record of climate-induced changes in lowland vegetation of eastern equatorial Africa revealed by the stable carbonisotopic composition of fossil plant leaf waxes. Earth Planet. Sci. Lett. 302, 236-246.

Versteegh, G.J.M., Schefuß, E., Dupont, L., Marret, F., Sinninghe Damsté, J.S., Jansen, J.H.F., 2004. Taraxerol and Rhizophora pollen as proxies for tracking past mangrove ecosystems. Geochim. Cosmochim. Acta 68, 411-422. 